\title{
Análise da saúde docente em uma escola municipal de Porto Alegre*
}

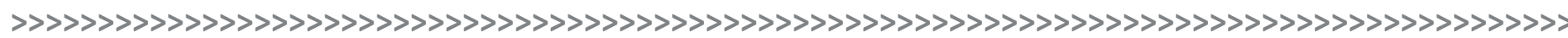

Aline Rocha Mendes**

\section{Resumo:}

O presente trabalho apresenta parte dos resultados encontrados em uma pesquisa, realizada no PPGEdu-PUCRS, de cunho quantitativo, que objetivou detectar e analisar as condições de mal-estar e bem-estar de 30 professores de uma escola do Ensino Fundamental da Rede Municipal de Ensino de Porto Alegre-BR, por meio de informações sobre suas licenças para tratamento de saúde (LTS), verificando-se que $35,4 \%$ dos professores solicitaram esta concessão; e respostas a um questionário de avaliação do Bem/Mal-estar Docente, analisadas com Estatística Descritiva e Inferencial. $\mathrm{Na}$ análise das variáveis do questionário, inferiu-se que estes educadores parecem querer continuar na profissão docente, com metas e expectativas elevadas para si e para seus educandos, embora tenham apresentado índices elevados de estresse e exaustão. Os resultados da investigação foram divulgados na escola pesquisada, dando-se assim um retorno aos docentes.

\section{Palavras-chave:}

Saúde docente. Mal-estar docente. Bem-estar docente. Licença para tratamento de saúde.

\section{Resumen:}

Este artículo presenta parte de los resultados encontrados en una investigación realizada en PPGEdu-PUCRS, de naturaleza cuantitativa, con el objetivo de detectar y analizar las condiciones de malestar y bienestar de 30 maestros de una escuela primaria de la Red Municipal de Enseñanza de Porto Alegre-BR, a través de la información sobre sus licencias para tratamiento de salud (LTS), se encontró que 35,4\% de los docentes solicitó esta subvención; y respuestas a un cuestionario de evaluación de bien/malestar docente, analizadas con estadística descriptiva e inferencial. En el análisis de las variables del cuestionario, se infiere que estos educadores parecen querer continuar en la profesión docente, con metas y estándares altos para sí mismos y sus estudiantes, a pesar de que mostraron altos niveles de estrés y agotamiento. Los resultados de la investigación fueron presentados en la escuela estudiada, dando así una retribución a los maestros.

\section{Palabras-clave:}

Salud docente. Malestar docente. Bienestar docente. Licencias para tratamiento de salud.
* $>$ Artigo produzido no Grupo de Pesquisa Mal/Bem-estar na Docência (CNPq/PUCRS), liderado pelo Prof. Dr. Claus Dieter Stobäus.

** > Professora da Rede Municipal de Ensino de Porto Alegre, Doutora e Mestre em Educação (PUCRS), Membro do Grupo de Pesquisa Mal/Bem-estar na Docência (CNPq/PUCRS), Especialista em Gestão da Educação (PUCRS), Licenciada em Ciências Biológicas (PUCRS).

E-mail: alinerochamendes@gmail.com 


\section{Introdução}

Na pesquisa de Mendes (2011) foi examinada a saúde docente, na perspectiva de superação de uma condição de mal-estar para o bem-estar e a realização profissional, em alguns dos professores de uma escola da Rede Municipal de Ensino de Porto Alegre, durante a elaboração de uma dissertação no curso de Mestrado em Educação, no Programa de Pós-Graduação da Faculdade de Educação da PUCRS.

Percebe-se que nos últimos anos ocorre, em um crescente, a situação de um número elevado de professores que solicita licença para tratamento de saúde. Esta circunstância é um fenômeno mundial, sendo que a profissão docente é uma das que gera mais afastamentos do trabalho por motivo de doença. Ainda assim, percebe-se que não existem dados nem encaminhamentos suficientes, numa perspectiva de apoio a estes docentes, nem avanços de soluções para melhoria das condições de trabalho a que os professores estão submetidos, que os levam a este adoecimento crescente.

A saúde do professor, até então, nunca foi levada em consideração na construção de políticas públicas, propostas em nível de sistemas de ensino e próprias nas unidades escolares, o que se pode avaliar como uma falha ou mesmo omissão por parte dos órgãos responsáveis e pelos gestores, na criação e implantação de propostas pedagógicas.

Frente a esta realidade torna-se relevante a demonstração da importância de maiores investimentos em pesquisas e estudos sobre aspectos do cotidiano do professor, sobre o que os leva a adoecerem, pois, geralmente, os dados são relacionados aos seus alunos, dificultando a promoção de ações concretas voltadas ao bem-estar docente.

A relevância e a justificativa deste estudo volta-se, evidentemente, para a vida profissional e pessoal dos professores, para sua saúde, bem-estar e para que atinjam-se melhores resultados nos processos de ensino e, consequentemente, obtenham-se repercussões em melhores aprendizagens discentes e docentes.

\section{Referencial Teórico}

Há aproximadamente duas décadas, percebe-se que o papel exercido pelos educadores e cobrado pela sociedade vem se modificando rapidamente. As expectativas aumentaram e as obrigações ficaram mais difusas.

Os docentes estão perigosamente sobrecarregados, têm mais responsabilidades como assistentes sociais, psicólogos, terapeutas e outros profissionais da área social e da saúde, do que verdadeiramente docentes.

O sistema escolar não oferece, muitas vezes, um número adequado de profissionais às instituições e esta lacuna reflete-se nas salas de aula, que são superlotadas de crianças, adolescentes e jovens em seus diversos níveis, tornando bastante difícil manter um clima adequado para a aprendizagem, que é a real competência da escola, dizem Gasparini, Barreto e Assunção (2005).

Nesse cenário, encontram-se docentes desmotivados, sofrendo de baixa auto-estima e que sentem-se desvalorizados pelo sistema de ensino e pela sociedade, representada pelos próprios pais destes alunos e pela massacrante e constante (des)informação da mídia.

Todas estas contradições enfrentadas pelos docentes leva-os a um processo de adoecimento pelo trabalho, ou seja, para o professor conseguir atingir os objetivos da produção escolar, precisa gerar enormes esforços de suas funções biopsicossociais, resultando em um processo denominado mal-estar docente.

Esteve (1999, p. 25) relata que diversos autores, desde a década de 1950, vêm empregando o termo mal-estar docente, que ele define por “[...] os efeitos permanentes de 
caráter negativo que afetam a personalidade do professor como resultado das condições psicológicas e sociais em que se exerce a docência”. O autor ainda acrescenta acerca do mal-estar docente que:

[...] é uma doença social produzida pela falta de apoio da sociedade aos professores, tanto no terreno dos objetivos do ensino como no das recompensas materiais e no reconhecimento do status que lhes atribui. (ESTEVE, 1999, p. 144)

Mosquera e Stobäus (2001, p. 25) complementam que a doença social “[...] provoca a pessoal”, explicando que há repercussões na saúde do professor de forma individual, pois o sujeito é que precisará se tratar.

Blase (1982, apud ESTEVE, 1999) classifica os fatores geradores de mal-estar docente como primários e secundários. Os primários são aqueles que incidem diretamente na ação dos professores e podem provocar tensões de caráter negativo em sua prática pedagógica. Citam-se alguns deles: a escassez de recursos materiais e precárias condições de trabalho que estão ligados à docência, a violência instituída nas escolas, incluindo-se o relacionamento tenso entre docentes e discentes e a acumulação de exigências sobre o educador. Já os fatores secundários são mais amplos e podem comprometer a eficácia do docente ao provocarem uma redução na motivação para o trabalho, quais sejam: a desvalorização do papel do professor, a crise de identidade profissional e a falta de suporte social.

Esteve (1999) também explica alguns efeitos do mal-estar na prática docente: insatisfação com o trabalho realizado; desenvolvimento de esquemas de distanciamento, para reduzir a implicação pessoal no trabalho; pedidos de transferência de escola; desejo de abandonar a docência; absenteísmo; esgotamento; cansaço físico, mental e emocional; ansiedade; estresse; além de doenças físicas, transtornos mentais e psicossomáticos.

Ainda neste contexto adverso e pouco favorável da educação, encontramos professores que estão satisfeitos com seu ofício e sentem-se realizados com ele, ou seja, sentem bem-estar. Portanto, enfocar-se-á agora nos estudos que seguem na direção da promoção da saúde e do bem-estar docente.

O conceito de saúde adotado neste trabalho vem de Conceição (1994, p. 5), que avalia a saúde de forma dinâmica e diz que "[...] ter saúde significa ser ativo permanentemente no ambiente em que vive, mantendo, modificando, criando tudo em conformidade com suas aspirações por uma melhor vida-saúde pessoal e comunitária”. Entende-se, portanto, que uma pessoa saudável é aquela que ao interatuar com o seu meio conserva sua individualidade biológica, reduzindo os desequilíbrios, solucionando os conflitos advindos desse intercâmbio.

A Psicologia Positiva é um campo que centra suas pesquisas em conhecer os mecanismos utilizados pelas pessoas que conseguem ter, mesmo diante de todas as adversidades do cotidiano, uma vida com satisfações pessoais/profissionais e saúde. Seligman e Csikszentmihalyi (2000, p. 5), definem que “[...] o objetivo da psicologia positiva é começar a catalizar uma mudança no foco da Psicologia da única preocupação com o reparo das piores coisas da vida para também construir as qualidades positivas”.

Atualmente, Seligman (2011) coloca que o bem-estar é o principal construto da Psicologia Positiva. Também explica que existem cinco elementos que contribuem para compreensão do bem-estar: emoção positiva, engajamento, sentido, relacionamentos positivos e realização.

O conceito de bem-estar utilizado neste trabalho considera que ele é "[...] o resultado da orientação geral positiva do sujeito para os acontecimentos de vida", como afirmaram Jesus e Rezende (2009, p. 17), pois depende não tanto das experiências do sujeito, mas de como este sujeito encara, avalia e resolve as mesmas. 
No que diz respeito ao bem-estar docente, Jesus (2007, p. 26) define que:

O conceito de bem-estar docente pode ser traduzido pela motivação e realização do professor, em virtude do conjunto de competências (resiliência) e de estratégias (coping) que este desenvolve para conseguir fazer frente às exigências e dificuldades profissionais, superando-as e otimizando o seu próprio funcionamento.

$\mathrm{Na}$ realidade, este conceito de bem-estar é bastante amplo e pode servir para qualquer profissão. Para que exista bem-estar é necessário que se goste da profissão e se queira buscar estratégias e novos conhecimentos para ampliar as possibilidades de sucesso profissional e pessoal. Portanto, acredita-se que o próprio educador pode e deve investir em seu bem-estar, valendo-se de alguns elementos que possibilitem um melhor cuidado de si, como por exemplo: a resiliência, o coping, a afetividade, a formação continuada etc.

A resiliência é uma capacidade, inerente aos seres humanos, que os faz resistirem às dificuldades e as adversidades da vida conservando sua essência, mesmo que tenha que se adaptar e se modificar conforme as situações experienciadas, de acordo com Tavares (2001). Nesta perspectiva, entende-se que a resiliência pode ser estimulada e aprimorada ao longo da vida e também pode ser desenvolvida por grupos. Os professores que desenvolvem melhor sua resiliência têm mais chance de terem bem-estar.

Pode-se compreender o coping como o conjunto de estratégias ou recursos utilizados pelos sujeitos para resolver situações de estresse, que sejam diferentes daquelas em que o sujeito está habituado a lidar (LAZARUS; FOLKMAN, 1984). Neste caso, os educadores que mais bem souberem utilizar estratégias de coping para lidar com as situações estressantes sairão delas menos desgastados.

Mosquera e Stobäus (2008, p. 77) destacaram que o docente deve estar educado para a afetividade, tendo em vista que, ao lidar com as diversidades no contexto escolar precisam ter respeito e empatia para compreensão do outro, e com o próprio inacabamento como condição humana, pois “[...] melhores relações interpessoais pressupõem a busca da saúde pessoal e social, resistir a uma sociedade e um mundo que tenta sempre colocar modelos de retrocesso e imposição". Quando as pessoas conscientizam-se de seus sentimentos, tornam-se, dessa forma, mais competentes para a tomada de decisões, tanto de caráter pessoal quanto profissional. No contexto escolar esse conhecimento da afetividade torna-se peça-chave para se criar um cotidiano mais saudável e com menos conflitos, estabelecendo-se relações intra e interpessoais que sejam profícuas e que frutifiquem em aprendizagens cognitivo-emocionais significativas.

Em 1996, Jesus já mencionava que para ser um bom professor é necessário desenvolver competências e qualidades relacionais, e salienta também que "[...] a formação de professores deve ser mais um processo de 'tornar-se', do que apenas obter informações sobre como ensinar" (JESUS, 2007, p. 39). Os professores precisam ser orientados a buscar em si as respostas de como melhor atuar, e aprender a se responsabilizar pelo seu crescimento profissional. Isso se aplica tanto à formação inicial como à continuada.

Se esses elementos de cuidado de si fossem praticados, poderiam, certamente, prevenir os processos de adoecimento docente. O nível de frustração em relação ao dia-adia escolar diminuiria, uma vez que os educadores já estariam mais bem preparados para lidar com este cotidiano. 


\section{Metodologia}

Relatar-se-á sobre alguns dos elementos, analisados de forma quantitativa, que fazem parte da pesquisa de Mendes (2011). Esta pesquisa foi aprovada pelos Comitês de Ética da PUCRS e da Secretaria Municipal da Saúde de Porto Alegre (SMS), e teve como objetivo principal detectar e analisar as condições de mal-estar e bem-estar de professores de uma escola do Ensino Fundamental da Rede Municipal de Ensino de Porto Alegre-BR. Além disso, comparou-se as médias de referência das variáveis do questionário utilizado (JESUS, 1996) com as médias obtidas nesse estudo (MENDES, 2011), tendo em vista encontrar dados mais precisos do ponto de vista estatístico, consequentemente qualificando a análise dos resultados.

A escola da Rede Municipal de Ensino de Porto Alegre que serviu como espaço de pesquisa localiza-se em um bairro periférico da cidade de Porto Alegre, funciona nos turnos da manhã, tarde e noite, e atende alunos de todos os ciclos do Ensino Fundamental e da Educação de Jovens e Adultos, com aproximadamente 1300 estudantes matriculados. O corpo docente era composto de 96 professores em 2010.

O grupo de 96 professores foi acompanhado durante seis meses $\left(1^{\circ}\right.$ semestre de 2010), em relação aos afastamentos para tratamento de saúde, através de dados recebidos na SMS, com contatos na Gerência de Saúde do Trabalhador, que forneceu dados anônimos sobre o tempo de afastamento e suas causas.

Participaram da pesquisa, com respostas a questionários, 30 docentes que tinham entre 28 e 64 anos de idade, com uma idade média de 48 anos. Eles tinham, em média, 16 anos de ingresso na Prefeitura Municipal de Porto Alegre, e em média 12 anos de atuação na escola.

Os professores responderam ao Instrumento para Avaliação das Variáveis que constituem Indicadores do Bem/Mal-Estar Docente, de Jesus (1996), que foi gentilmente cedido pelo autor para seu uso neste estudo.

A análise dos resultados foi feita com Estatística Descritiva e Inferencial.

\section{Análise dos Resultados}

A partir dos dados recebidos da SMS em relação às licenças para tratamento de saúde (LTS) solicitadas pelos docentes, foram feitas algumas análises.

Verificou-se que, de um grupo de 96 professores, 34 estiveram em LTS, no primeiro semestre de 2010, perfazendo $35,4 \%$ deste coletivo, o que pode ser considerado como alto, visto que, em entrevista informal na Gerência de Saúde do Servidor Municipal (GSSM), foi dito que até $8 \%$ é considerado um percentual normal. Analisando-se as solicitações por mês, somente em março é que as LTS se aproximaram-se deste normal, com 8,3\% de afastamentos por LTS. Nos meses de abril e maio $14,58 \%$ dos professores solicitaram LTS. Constatou-se que, em junho, ocorreram mais afastamentos, perfazendo $15,62 \%$ do total que docentes estiveram em LTS.

Em contrapartida, o mês de fevereiro teve o percentual mais baixo, 3,12\%, em janeiro encontrou-se 5,2\%, ressaltando-se este período como sendo de recesso escolar, mas alguns professores que estão em delimitação de tarefa acabam solicitando LTS. Nesta escola existem três professores na condição de delimitados de modo permanente, exercendo funções alheias à sala de aula, em razão do tipo de delimitação. 
Esteve (2005) em seus estudos em Málaga, Espanha, relatou que 21,31\% dos professores primários solicitaram afastamento por doença e este índice foi de $9,53 \%$ nos professores secundários. Por esses índices pode-se constatar que a situação desta escola não é a única, e a saúde dos docentes em nível mundial vem se degradando.

Ainda receberam-se as informações acerca das LTS e suas causas, utilizandose o Código Internacional das Doenças (OMS, 2008). Chama a atenção o tempo de afastamento nos transtornos mentais e comportamentais, já que este grupo gerou $57,26 \%$ dos dias totais de afastamentos, e 12,5\% dos professores da escola foi enquadrado em LTS com esta categoria de doença. Pode-se exemplificar como diagnóstico mais frequente a depressão.

Em segundo lugar, aparecem as licenças concedidas por convalescença após cirurgia, resultando em $12,58 \%$ dos dias de afastamentos, com 4,16\% de solicitantes. Pelos dados recebidos não há como saber o tipo de cirurgia.

Em terceiro lugar de LTS concedidas, estão as doenças do sistema osteomuscular e tecido conjuntivo, implicando em 9,92\% do total de dias de afastamento e envolvendo $5,2 \%$ do total de docentes da escola. Problemas em diferentes partes da coluna são as mais comuns.

Segundo Esteve (2005), os diagnósticos que mais produzem dias de trabalho perdidos em licenças são: $1^{\circ}$. traumatológicos (ex. tornozelo torcido), $2^{\circ}$. otorrinolaringológicos (ex. laringite) e $3^{\circ}$. psiquiátricos (ex. depressões).

Buscando-se outros estudos nesta temática encontrou-se o de Gasparini, Barreto e Assunção (2005), realizado com professores em Minas Gerais, a partir de informações da perícia médica da Prefeitura Municipal de Belo Horizonte. As pesquisadoras verificaram que $15,3 \%$ dos afastamentos docentes correspondiam a transtornos mentais e comportamentais; em segundo lugar, com $12,2 \%$ as doenças do aparelho respiratório e, na terceira posição as doenças do sistema osteomuscular e tecido conjuntivo representando 11,5\% das LTS.

Outra pesquisa, de Siqueira e Ferreira (2003), realizada em Florianópolis, com 150 professoras de séries iniciais, constatou que as principais causas das licenças são (em ordem decrescente): doenças do aparelho respiratório, problemas do aparelho locomotor e problemas psicológicos e/ou psiquiátricos.

Percebe-se que os resultados estão convergindo com os dados apresentados nesta pesquisa, levando a crer que a situação de saúde docente não muda muito quando contrastada a outros estados brasileiros.

Ainda pode-se ressaltar que a média de duração das LTS é de 8,54 dias, visto que os 34 professores requereram um total de 66 pedidos (várias pessoas solicitaram mais de uma LTS), gerando 564 dias de afastamento total. Além disso, verificou-se que a LTS mais longa ocasionou 76 dias de baixa, iniciando em março e terminando em final de maio de 2010.

Esteve (2005) comenta que a média de licenças em seu estudo mudou do início de 41 dias para 26,4 no final. Ele acredita que a inspeção médica tenha tornado-se mais rígida na avaliação ao longo do tempo.

Conjuntamente examinaram-se dados gerais da Rede Municipal de Ensino (RME) de Porto Alegre, conforme exposto no Gráfico 1: 


\section{Gráfico 1 - Incremento professores XLTS da RME}

Total de LTS de professores $(35,06 \%)$

Total de professores $(16,93 \%)$

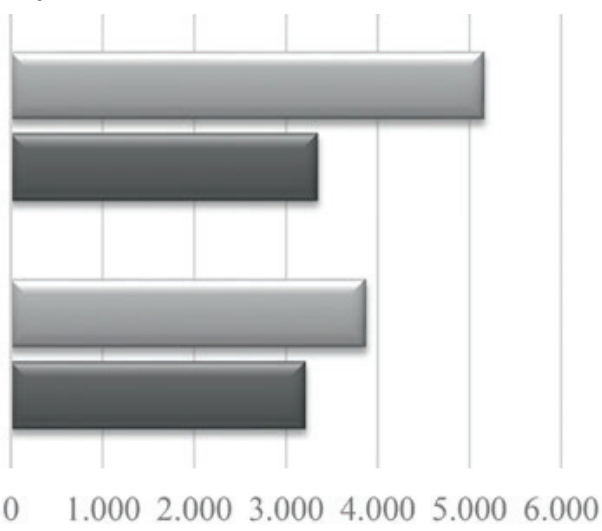

$\square$ Ano de 2008 - Ano de 1998

Fonte: Dados da pesquisa, 2016.

Entre os anos de 1998 e 2008 houve um aumento de 16,93\% no número de professores servidores da RME. Em contraste, neste mesmo período houve um crescimento de $35,06 \%$ no número de afastamentos para tratamento de saúde.

Através dos índices analisados, pode-se afirmar que, por exemplo, o percentual de professores em LTS teve um aumento progressivo nos últimos 10 anos, maior do que o incremento de professores que ingressaram na Rede no mesmo período, denotando uma deterioração das condições de saúde docente.

Pode-se inferir que a realidade da Rede e da escola estudada não difere muito da situação mundial da (falta de) saúde docente. Concorda-se com Esteve (2005) quando indica que os professores que tem LTS prolongadas deveriam ter um atendimento diferenciado no setor de saúde, um tipo de reabilitação posterior às licenças.

Pensa-se que, no contexto pesquisado, poderiam ocorrer ações integradas entre a Gerência de Saúde e as escolas, com a coordenação conjunta por parte da Secretaria de Educação, para melhor acolhimento dos docentes que têm problemas que podem se tornar crônicos. O autor também destaca que o professor que volta de uma licença prolongada por motivos psiquiátricos ou vocais, por exemplo, e retorna à mesma situação de trabalho, provavelmente terá, em breve, as mesmas dificuldades e irá se ausentar novamente, ou seja, o ciclo de doenças continuará ocorrendo.

Aplicou-se o instrumento desenvolvido pelo Prof. Dr. Saul Neves de Jesus (1996), em sua tese de doutorado, cujo título é A motivação para Profissão Docente. Contributo para a clarificação de situações de mal-estar e para a fundamentação de estratégias de formação de professores, que foi cedido por ele para o uso neste estudo. O autor utilizou este instrumento na fase de sua elaboração, em professores e potenciais professores portugueses $(\mathrm{N}=143)$ dos ciclos finais do ensino básico e secundário, em Coimbra.

Este instrumento conta com 113 questões, que são agrupadas em dezesseis variáveis avaliadas. A maioria das questões são 'fechadas', isto é, demandam que o sujeito escolha uma resposta em uma escala do tipo likert, com vários graus de resposta possível. Antes de cada grupo de questões é apresentado o significado dos algarismos que podem representar as respostas e um resumo do que é avaliado naquela variável. No livro Bem-estar dos professores: estratégias para realização e desenvolvimento profissional, Jesus (1998) descreve esse questionário e o Programa de formação para prevenção do mal-estar docente. O autor propõe que, a partir da avaliação pelo instrumento (comparação com as médias), os docentes podem favorecer sua situação profissional e pessoal participando da formação. Este Programa tem o intuito de, com a formação continuada, instrumentalizar professores a lidar melhor com seu cotidiano profissional. 
Na Tabela 1 são apresentados os resultados da comparação entre as médias obtidas pelo autor e as médias deste estudo, por meio do teste t.

Tabela 1 - Resultados das médias das variáveis dos estudos em Portugal (JESUS, 1996) e em Porto Alegre (MENDES, 2011).

\begin{tabular}{|c|c|c|c|c|c|c|c|}
\hline & Variáveis & $\begin{array}{l}\text { Médias } \\
\text { Jesus } \\
(1996), \\
N=143\end{array}$ & $\begin{array}{l}\text { Desvio } \\
\text { padrão } \\
\text { Jesus }\end{array}$ & $\begin{array}{c}\text { Médias } \\
\text { Mendes } \\
(2011), \\
N=30\end{array}$ & $\begin{array}{l}\text { Desvio } \\
\text { padrão } \\
\text { Mendes }\end{array}$ & $\begin{array}{l}\text { Valor } \\
\text { de } t\end{array}$ & $\begin{array}{l}\text { Moda } \\
\text { Mendes } \\
\text { (2011) }\end{array}$ \\
\hline & $\begin{array}{l}\text { Avaliação do projeto } \\
\text { profissional }\end{array}$ & 4,413 & 1.663 & 4,46 & 1,5434449 & $-0,150$ & 6 \\
\hline & $\begin{array}{l}\text { Avaliação do empenho } \\
\text { profissional }\end{array}$ & 62,874 & 7.747 & 61,5 & 10,272131 & 0,692 & 72 \\
\hline & $\begin{array}{l}\text { Avaliação do valor } \\
\text { das metas profissionais }\end{array}$ & 30,615 & 2.584 & 30,66 & 2,5862886 & $-0,087$ & 33 \\
\hline & $\begin{array}{l}\text { Avaliação da motivação } \\
\text { intrínseca }\end{array}$ & 22,462 & 3.711 & 24,33 & 6,5081146 & $-1,521$ & 28 \\
\hline & $\begin{array}{l}\text { Avaliação da expectativa } \\
\text { de eficácia }\end{array}$ & 29,517 & 4.007 & 30,4 & 5,8742375 & $-0,786$ & 34 \\
\hline & $\begin{array}{l}\text { Avaliação da expectativa } \\
\text { de controle }\end{array}$ & 44,846 & 5.693 & 44,9 & 6,4257295 & $-0,043$ & 45 \\
\hline & $\begin{array}{l}\text { Avaliação das atribui- } \\
\text { ções causais: }\end{array}$ & & & & & & \\
\hline & Sucessos (locus) & 22,5 & 2.936 & 22,86 & 4,1370951 & $-0,453$ & 24 \\
\hline & Fracassos (locus) & 16,3 & 6.030 & 12,93 & 7,288957 & 2,368 & 4 \\
\hline & Sucessos (estabilidade) & 16,3 & 2.481 & 16,86 & 3,1699982 & $-0,911$ & 18 \\
\hline & Fracassos (estabilidade) & 11,4 & 4.838 & 9,16 & 5,164516 & 2,183 & 3 \\
\hline & $\begin{array}{l}\text { Avaliação do estresse } \\
\text { profissional }\end{array}$ & 317,594 & 101.267 & 384,53 & 125,3065 & $-2,744$ & \\
\hline & $\begin{array}{l}\text { Avaliação da exaustão } \\
\text { profissional }\end{array}$ & 428,783 & 254.423 & 607,33 & 492,52515 & $-1,932$ & \\
\hline & $\begin{array}{l}\text { Avaliação das crenças } \\
\text { irracionais }\end{array}$ & 39,09 & & 38,7 & 5,8943476 & & 36 \\
\hline & $\begin{array}{l}\text { Avaliação das estratégias } \\
\text { de coping }\end{array}$ & 23,568 & & 24,33 & 4,6284147 & & 26 \\
\hline $\begin{array}{l}1>\text { Foram considerados resultados signi- } \\
\text { ficativos ao nível de } 5 \% \text { (alfa=0.05). Nas }\end{array}$ & $\begin{array}{l}\text { Avaliação do sucesso } \\
\text { profissional }\end{array}$ & 26,943 & 3.296 & 28,5 & 3,253204 & $-2,378$ & 28 \\
\hline $\begin{array}{l}\text { de coping não se obteve o desvio padrão } \\
\text { paração. Nas variáveis estresse e exaustão }\end{array}$ & $\begin{array}{l}\text { Avaliação da motivação } \\
\text { inicial para a profissão } \\
\text { docente }\end{array}$ & 26,757 & 4.645 & 25,4 & 5,9475485 & 1,177 & 23 \\
\hline
\end{tabular}


Pode-se observar pela Tabela 1 que a maioria das médias das variáveis que obtevese neste estudo são similares com as do autor do instrumento.

Em quatro variáveis há diferença significativa entre as médias dos dois estudos, quais sejam, atribuições causais - fracassos nas dimensões locus e estabilidade, o estresse profissional e o sucesso profissional, para tanto se comparou as médias percentuais dos dois estudos, considerando-se significativo os resultados em nível de $5 \%$ (alfa $=0,05$ ).

Na variável atribuições causais para o fracasso, na dimensão locus, os pesquisados apresentaram uma pontuação menor que a média de Jesus (1996), e na dimensão estabilidade pontuaram menos que a média do mesmo autor. Nestas dimensões, que buscam explicar as causas dos fracassos, entende-se que os docentes brasileiros atribuem mais a razões externas e instáveis como motivos de seus fracassos do que os professores portugueses.

$\mathrm{Na}$ variável estresse profissional os professores brasileiros apresentaram mais pontuação que os portugueses, revelando-se mais afetados ao tentar motivar os alunos que não querem aprender, ao controlar a indisciplina na sala de aula e, muitas vezes, não ser bem-sucedidos.

Na variável sucesso profissional os professores brasileiros apresentaram uma média significativamente maior do que os portugueses, o que denota uma melhor percepção de sucesso nos professores brasileiros.

Jesus (1998) sugere que os docentes indicados a participar de programa de prevenção ao mal-estar docente seriam aqueles que apresentassem resultados inferiores à média nas medidas de projeto profissional, empenhamento profissional, valor das metas, motivação intrínseca, expectativa de eficácia, expectativa de controlo, atribuição causal, motivação inicial e sucesso profissional e superiores à média nas medidas de estresse e exaustão profissional, crenças irracionais e estratégias de coping. Em razão dessas orientações para a avaliação do instrumento que o autor propõe é que optou-se por fazer a comparação entre as médias de Coimbra/Portugal e Porto Alegre/Brasil, por meio do teste t, para buscar um resultado mais preciso a partir das médias de referência do instrumento.

Estes resultados demonstram que, esta escola, a partir da amostra destes docentes, poderia adotar um programa de prevenção ao mal-estar docente. Indica-se isto devido às altas médias apresentadas no estresse e na exaustão profissional, embora as outras variáveis tenham ficado com valores aproximados das médias de referência do instrumento. No entanto, percebe-se que esses valores são importantes para indicar a presença de mal-estar docente, tendo em vista ainda os dados já introduzidos a respeito do número elevado de licenças médicas $(35,4 \%)$ do grupo estudado.

Ademais, calculou-se, na tabela 1, a moda de cada variável, ou seja, o valor que ocorreu com maior frequência entre as respostas computadas, objetivando-se construir um perfil qualitativo dos pesquisados, a partir das variáveis analisadas.

Neste sentido, os resultados da moda expressaram que este grupo de professores parecem querer continuar na profissão docente, mostrando-se empenhados em sua atuação pedagógica e com metas e expectativas elevadas para si e para seus educandos. Avaliam, com certo grau de sucesso, suas realizações profissionais relacionadas com sua ação pedagógica frente seus alunos.

A respeito da motivação intrínseca parecem ver sentido em sua profissão, independentemente de um fator externo de recompensa. Veem-se como eficazes no sentido das estratégias de ensino que utilizam na escola. Denotam uma orientação inicial para profissão docente um pouco menor do que os professores portugueses, mostrando-se com uma motivação inicial mais baixa. 
Os pesquisados demonstraram que se sentem pessoalmente implicados para atingir resultados na aprendizagem de seus educandos, exposto nos resultados da variável expectativa de controle. Quanto às atribuições causais, remetem seus sucessos a causas mais internas e estáveis (ex: competência profissional) e os fracassos a causas mais externas e instáveis (ex: falta de reconhecimento dos alunos).

No que diz respeito aos resultados do estresse e da exaustão profissionais, não foi possível calcular a moda, pois os dados têm ampla variabilidade preferiu-se, portanto, verificar os valores mais altos e mais baixos encontrados. O professor que teve o resultado mais baixo no estresse marcou 132 pontos, enquanto o que teve o maior resultado fez 575 pontos (valor mínimo de 25 e máximo de 625). Na exaustão profissional, o docente que apresentou o resultado mais baixo fez 64 pontos e o mais alto foi de 2184 (valor mínimo de 64 e máximo de 2240).

Jesus (1996) verificou que há uma correlação entre um alto grau de exaustão e o desejo de abandonar a profissão. Neste estudo o pesquisado que mais pontuou na variável exaustão fez dois pontos na avaliação do projeto profissional (de um mínimo de zero e um máximo de seis nesta variável).

Em relação a este estudo acredita-se que os altos índices apresentados pelo grupo nas variáveis acima citadas estão envolvidos com a questão social dos alunos aos quais atendem. Os estudantes têm uma condição social bastante carente e necessitam de atendimentos e de ajudas, nas áreas da assistência social e da saúde, as quais nem os professores nem a escola podem dar, gerando uma sobrecarga e frustração que pode se transformar em estresse e exaustão.

\section{Formação na escola pesquisada}

Como forma de dar um retorno ao grupo de docentes da escola, organizou-se uma apresentação dentro do ciclo de formações da escola, que aconteceu na manhã de 24 de março de 2012. Participaram da formação aproximadamente 65 docentes, sendo que alguns participaram da pesquisa e outros não. Foram apresentados os principais referenciais teóricos que embasaram este estudo, os resultados e a análise dos mesmos.

Durante a exposição os professores interferiram questionando e contribuindo com exemplos de suas vivências pessoais e profissionais. Segue o relato de algumas das impressões e análises elaboradas a partir das reações e contribuições feitas pelos docentes naquela formação.

Os professores passaram a conhecer conceitos como de mal-estar, de saúde, de bem-estar e psicologia positiva, dentro da perspectiva delineada no referencial teórico. Quando foi apresentada a questão da importância do vínculo afetivo com os alunos para o sucesso da aprendizagem, foi impactante para muitos colegas, pois foram muitas as participações neste tópico, incluindo pessoas que se colocaram com dificuldade de estabelecer este vínculo, como outros que concordaram e dizem que somente assim conseguem chegar ao aluno.

Tiveram bastante interesse na parte dos dados das licenças para tratamento de saúde, pois estavam vendo de forma organizada informações que costumam obter de maneira informal e, muitas vezes, imprecisa na escola. Buscou-se enfatizar que aqueles números são da escola, mas refletem um contexto maior, na tentativa de mostrar o que acontece, sem a intenção de culpar os educadores, e sim de delinear um problema que precisa de várias ações do poder público para que possa se alterar. Algumas pessoas manifestaram que já sentiram preconceito do grupo por estarem afastados da escola, outros disseram que há pessoas que saem em licença prolongada e prejudicam muitos alunos 
e os professores que ficam trabalhando. Com isso, evidencia-se mais uma contradição que os sistemas de ensino e de saúde impõem às escolas criando um clima negativo no grupo, enquanto deveriam trazer soluções, tanto para os que estão em licença, quanto para os que estão no serviço.

Destaca-se a parte do estresse profissional nas variáveis do instrumento de indicadores de mal/bem-estar docente, colocado por Jesus (1996), que neste grupo teve percentuais significativamente mais altos do que a média do seu trabalho, relatando os docentes que também aceitaram a análise apresentada, mas veem-se como profissionais comprometidos.

Dizem que ficam extenuados com a rotina que precisam atender, principalmente com a falta de apoio de outros setores que precisam ajudar a educação (assistência social, inclusão e saúde), como também das famílias dos seus educandos e da própria Secretaria Municipal da Educação, que interfere na avaliação do trabalho pedagógico, mas não oferece o apoio necessário.

Foi sugerido pelo grupo que a dissertação de Mendes (2011), intitulada Saúde docente: uma realidade detectada - em direção ao bem-estar e a realização profissional, seja encaminhada a Secretaria de Educação do Município de Porto Alegre para que a situação torne-se de conhecimento público, embora tenham colocado que não acreditam que a melhora da saúde do professor se constitua em um objetivo para o poder público.

Quanto à avaliação da formação, muitos professores falaram diretamente com a pesquisadora, explicitando que haviam gostado bastante do tema e do modo como foi feita a dinâmica de apresentação. Referiram-se também a relevância deste assunto e de como careciam de espaços de formação e planejamento em serviço em que pudessem debater mais sobre sua profissão e aspectos que realmente os ajudassem em sua prática docente.

A pesquisadora também avaliou como muito positiva essa formação, considerando bastante gratificante ter este momento para compartilhar conhecimento com seus pares que contribuíram de forma tão honesta e aberta.

Observando-se as repercussões aqui descritas pode-se inferir que este grupo esteja interessado em participar de um programa de formação continuada, voltado para tópicos que efetivamente pudessem instrumentalizá-los a melhor resolver os problemas que enfrentam em seu cotidiano profissional, e que também tem reflexos em sua vida/ saúde pessoal.

\section{Considerações finais}

Retomando-se o objetivo deste estudo, que foi o de detectar e analisar as condições de saúde, mal-estar e bem-estar de professores de uma escola da Rede Municipal de Ensino de Porto Alegre, encontrou-se níveis preocupantes de afastamentos por motivo de doenças, embora os docentes que responderam aos questionários tenham apresentado uma tendência ao bem-estar, mesmo obtendo índices altos de estresse e exaustão.

Durante a pesquisa foi demonstrado que houve na escola pesquisada um percentual alto de professores em licença para tratamento de saúde (LTS) no primeiro semestre de 2010. Também foi levantado que, em um intervalo de dez anos (1998 e 2008), houve um progressivo aumento das LTS em toda a Rede. Todos esses dados indicam que há uma deterioração ocorrida no bem-estar e na saúde docente, o que faz parte de um cenário mundial e não exclusivo da Rede. Também não se teve notícias, pelo menos explícitas, de medidas ou programas, por parte da Secretaria Municipal da Educação, em especial conjuntamente com a Secretaria Municipal da Saúde, para revisão e possível reversão deste quadro. 
Com a análise do questionário de avaliação dos indicadores de mal/bem-estar docente, ficou expresso que os participantes do estudo apresentaram índices elevados de estresse e exaustão, mas, ainda assim, sentiram-se entusiasmados com sua profissão e revelaram uma crença na importância de seu trabalho para a construção de uma sociedade melhor, que lhes fortalece como pessoa e faz com que tenham bem-estar, provavelmente por apresentarem resiliência e estratégias positivas de enfrentamento e superação, entre elas possivelmente o apoio de familiares, colegas e da direção.

Para que exista uma melhora concreta das condições de saúde destes professores existem elementos constituintes de seu ofício que precisam ser modificados. Alguns desses itens precisam de investimento em políticas públicas em nível sistêmico, prescindindo da ação direta dos professores, para que possam ser alterados e superados, quais sejam: a violência escolar; a burocracia instituída como parte do trabalho; o excesso de alunos na sala; os baixos salários e um plano de carreira deficitário; a formação deficitária; os recursos materiais e didáticos escassos; o excesso de períodos semanais em sala de aula, sobrando pouco espaço para o planejamento pedagógico individual e coletivo; um serviço de saúde técnico que não auxilia diretamente nos problemas de saúde dos professores, entre outros.

Indiretamente, para que essas mudanças aconteçam, é necessária a atuação mais cidadã destes docentes, em suas organizações de classe e nas instituições em que atuam, para firmar os posicionamentos que favoreçam sua condição profissional, com isso também qualificando o ensino e a aprendizagem.

Em contrapartida, existem situações do contexto escolar que podem ser modificadas pelo próprio professor, tais como: qualificação das relações interpessoais com colegas, educandos e famílias; busca de sua formação continuada; construção de parcerias de trabalho com colegas e estudantes a fim de superar o individualismo e a fragmentação; gerenciamento da relação trabalho X vida pessoal, organizando tempo para ambos; busca do autoconhecimento para melhor lidar consigo e ter mais alteridade e conhecimento do cotidiano dos estudantes, do local onde eles vivem para melhor situar sua prática pedagógica nesta realidade.

Após as reflexões e análises dos contextos já apresentados, pode-se perceber que a questão da saúde dos docentes desvela fatos muito preocupantes, pois os adoecimentos se ampliam, as condições de trabalho degradam-se e ainda faltam avanços e progressos a serem construídos no que tange à saúde docente. Principalmente, no que diz respeito às relações interpessoais e o bem-estar, vê-se que as carências são muitas e que os caminhos a serem percorridos por educadores, educandos, gestores, famílias e sistemas de ensino ainda são longos para se chegar às soluções para estes problemas.

Nos processos de construção de um cotidiano escolar mais produtivo, significativo e de sucesso para todos, são necessárias ações e medidas em diversas esferas: a governamental (políticas públicas e investimentos), a gestão escolar (programas de formação continuada e enfoque no sucesso escolar), a comunidade (participação ativa na escola) e a associação de professores, constituindo grupos de estudos e trabalho, tendo como dimensão norteadora as relações humanas calcadas no afeto e na empatia. Assim sendo, os professores sentir-se-ão mais apreciados, modificando a atual condição de estarem docentes estressados, mas ainda acreditando em seu trabalho, para educadores valorizados e com sucesso pessoal e profissional. 


\section{Referências}

CONCEIÇÃO, José Augusto Nigro (Coord.). Saúde escolar: a criança, a vida e a escola. 1. ed. São Paulo: Sarvier, 1994.

ESTEVE, José Manuel. O mal-estar docente: a sala de aula e a saúde dos professores. 3. ed. Bauru: EDUSC, 1999.

Bem-estar e saúde docente. Revista PRELAC. Santiago de Chile, n. 1, p. 116-33, jun. 2005.

GASPARINI, Sandra Maria; BARRETO, Sandhi Maria; ASSUNÇÃO, Ada Ávila. O professor, as condições de trabalho e os efeitos sobre sua saúde. Educação e Pesquisa, São Paulo, v. 31, n. 2, p. 189-199, maio/ago. 2005. Disponível em: <http://www.scielo.br/pdf/ep/v31n2/a03v31n2.pdf >. Acesso em: 24 ago. 2016.

JESUS, Saul Neves de. A motivação para profissão docente: contributo para a clarificação de situações de mal-estar e para a fundamentação de estratégias de formação de professores. 1. ed. Aveiro: Estante Editora, 1996.

Bem-estar dos professores: estratégias para realização e desenvolvimento profissional. 1. ed. Porto: Porto Editora, 1998.

Professor sem stress: realização profissional e bem-estar. 1. ed. Porto Alegre: Mediação, 2007.

JESUS, Saul Neves de; REZENDE, Manuel. Saúde e bem-estar. In: CRUZ, José; JESUS, Saul Neves de; NUNES, Cristina (Coord.). Bem-estar e qualidade de vida: contributos da Psicologia da Saúde. 1. ed. Porto: Textiverso, 2009. p. 11-25.

LAZARUS, Richard; FOLKMAN, Susan. Stress, appraisal, and coping. 1. ed. New York: Springer, 1984.

MENDES, Aline Rocha. Saúde docente: uma realidade detectada - em direção ao bem-estar e a realização profissional. 2011. 117fs. Dissertação (Mestrado em Educação)-Pontifícia Universidade Católica do Rio Grande do Sul, Porto Alegre, 2011.

MOSQUERA, Juan José Mouriño; STOBÄUS, Claus Dieter. O mal-estar na docência: causas e conseqüências. Revista da ADPPUCRS. Porto Alegre, n. 2, p. 23-34, nov. 2001.

MOSQUERA, Juan José Mouriño; STOBÄUS, Claus Dieter. O professor, personalidade saudável e relações interpessoais: por uma educação para a afetividade. In: ENRICONE, Délcia (Org.). Ser professor. Porto Alegre: EDIPUCRS, 2008. p. 67-78.

ORGANIZAÇÃO MUNDIAL DA SAÚDE (OMS). Classificação Estatística Internacional de Doenças e Problemas Relacionados à Saúde (CID-10). Disponível em: <http://www.datasus.gov.br/cid10/ v2008/cid10.htm>. Acesso em: 24 ago. 2016.

SELIGMAN, Martin. Florescer: uma nova compreensão sobre a natureza da felicidade e do bem-estar. 1. ed. Rio de Janeiro: Objetiva, 2011.

SELIGMAN, Martin; CSIKSZENTMIHALYI, Mihaly. Positive psychology. American Psychologist, Washington, v. 55, n. 1, p. 5-14, jan. 2000.

SIQUEIRA, Maria Juracy Toneli; FERREIRA, Edirê. Saúde das professoras das séries iniciais: o que o gênero tem a ver com isso? Psicologia, Ciência e Profissão, Brasília, v. 23, n. 3, p. 76-83, set. 2003. Disponível em: <http://www.scielo.br/pdf/pcp/v23n3/v23n3a11.pdf >. Acesso em: 24 ago. 2016.

TAVARES, José (Org.). Resiliência e educação. 1. ed. São Paulo: Cortez Editora, 2001. 